\title{
Metaphoric reference: When metaphors are not understood as easily as literal expressions
}

\author{
KRISTINE H. ONISHI \\ Brown University, Providence, Rhode Island \\ and \\ GREGORY L. MURPHY \\ University of Illinois, Urbana, Illinois
}

\begin{abstract}
Gibbs (1990) found that metaphoric referential descriptions take longer to read than literal references, in contrast to the usual result that metaphors and literal sentences are about equally easy to comprehend. This study was performed as an investigation of Gibbs's finding. In Experiment 1 , subjects received story contexts in which characters clearly shared knowledge relevant to the metaphoric referring term. In Experiment 2, we tried to ensure that the intended referent was very salient by mentioning it in the sentence just prior to the crucial sentence. Neither of these manipulations eliminated the large response time advantage for literal referring expressions. In Experiment 3, the same metaphors were used as sentence predicates rather than as referring expressions: the metaphors were no more difficult to understand than literal paraphrases. Possible explanations for the difficulty of metaphoric references, as opposed to metaphoric predicates, are discussed.
\end{abstract}

The metaphoric use of language is not uncommon or obscure. It occurs in everyday conversation, and sometimes it is not even recognized as being nonliteral. Rumelhart $(1979$, p. 79$)$ describes the following exchange. He was driving with his family, when his 8-year-old son said, “'Hey, Mom, my sock has a hangnail." His wife replied without surprise, "I'll fix it when we get home." 'Since no one but Rumelhart himself even noticed the nonliteral use of "hangnail," this anecdote suggests that there is nothing uncommon or difficult about comprehending nonliteral language. If figurative language is truly pervasive and easy to understand, any adequate theory of language comprehension should take both figurative and literal language into account.

Metaphor is often described as having three components (Richards, 1936, cited in Hoffman \& Honeck, 1980): a topic, a vehicle, and a ground. In the expression Meera is an icebox, the topic or subject is Meera. The vehicle is what is predicated of the topic, here an icebox. In most metaphors, there is an incompatibility or conflict between these two components. In fact, if the topic and vehicle are too closely related, the expression does not seem metaphoric (Tourangeau \& Sternberg, 1981). The ground is what can be seen as common between the two--coldness in the present instance, because physical temperature is equated with the range of emotions. If no ground can be found, the utterance is anomalous rather than figurative.

This research was supported by NIMH Grant MH41704. We are grateful to Richard Gerrig, Raymond Gibbs, and Sam Glucksberg for helpful comments on earlier versions of this article. Correspondence may be addressed to G. L. Murphy, Beckman Institute, University of Illinois, 405 North Mathews Ave., Urbana, IL 61801.
Several psychological theories of nonliteral language have been put forth. The traditional theory is that metaphoric comprehension is a later stage in the understanding process, following literal interpretation (for discussion, see Ortony, Schallert, Reynolds, \& Antos, 1978; Searle, 1979). When an utterance is heard, the truth conditions of its propositions are verified against the other available propositions of the discourse. If there is an incompatibility, the hearer tries to reinterpret the utterance in a way that maintains the cooperative principle (Grice, 1975). Therefore, the stages are (1) recognition of incompatible truth conditions or selectional restrictions in the literal meaning, (2) reconstruction of possible meanings, and (3) proper interpretation of the utterance (Miller, 1979). This stage theory entails both that literal meanings will always be derived first, because they must trigger the nonliteral interpretation, and that nonliteral interpretations are optional. That is, nonliteral interpretations do not occur unless there is a pragmatic or semantic violation.

One problem for stage theories is that a number of metaphors are not semantically anomalous and so would not trigger the second stage. Even so, they are easily interpreted as metaphoric (see Keysar, 1989; Reddy, 1969; Tourangeau, 1982).

A second problem, which will be the focus of this article, arises from studies of the time required for one to understand metaphors. There is evidence that with appropriate context, and contrary to the stage theory, literal interpretations are not necessarily derived before metaphoric ones (Gibbs \& Nagaoka, 1985; Ortony et al., 1978; Shinjo \& Myers, 1987). The argument is that “prior context allows the analysis of the literal interpretation of a metaphor to be truncated" (Gerrig \& Healy, 1983, 
p. 667). In addition, there is evidence that metaphoric interpretations are not optional, countering the other implication of stage theory. When subjects were asked to judge the literal falsity of sentences, metaphoric "truth" made the decision more difficult (Gildea \& Glucksberg, 1983; Glucksberg, Gildea, \& Bookin, 1982; Keysar, 1989), suggesting that metaphoric comprehension was at least as fast as literal processing. However, as we shall discuss next, more recent findings have unexpectedly provided support for the serial model.

Typically, researchers have studied predicative metaphors, as in the sentence $A n A$ is $a B$, in which the vehicle is used to describe an explicitly identified object $(A)$. Gibbs (1990) extended earlier work by examining metaphor used referentially. He asked whether such figurative reference acts as literal reference does, in reinstating its antecedent (see, e.g., Dell, McKoon, \& Ratcliff, 1983; O'Brien, Duffy, \& Myers, 1986). Gibbs did find that metaphoric anaphors reinstate their antecedents. However, he also found an unexpected result, that figurative reference took longer to comprehend than literal reference. For example, he showed that referring to a cowardly boxer as the creampuff took longer to understand than referring to the same person as the fighter. Metonymic references, in which a whole object is identified by a part or by an associated property (e.g., a reference to a baseball fielder as a glove), were hardest of all.

Gibbs's (1990) results are surprising and potentially quite important. As described above, many studies of metaphor comprehension have found little or no difference in ease of comprehension between similar literal and metaphoric sentences, especially when they occur in a supportive context. Why should metaphoric references be any different? Gibbs's results suggest that either there may be some validity to the stage view after all, or else the nature of reference somehow conflicts with the use of metaphor. More generally, it is possible that there are constraints on the phenomenon of metaphoric and literal sentences' being equally easy to comprehend. Our main goal in the present studies was to investigate this possibility. Our first step was to confirm Gibbs's results, by testing alternative explanations of his findings.

In Experiment 1, we hypothesized that the figurative reference took longer than the literal reference because the characters in the vignettes did not clearly share mutual knowledge that was necessary for one to interpret the metaphor. In Experiment 2, we hypothesized that the longer figurative reading times were caused by difficulty in accessing the intended referent, so we highlighted the referent just prior to the metaphor. To foreshadow the results, neither attempt altered the finding that metaphoric references were more difficult to comprehend. In Experiment 3 , we questioned whether it was the particular topic-vehicle combinations used that made the metaphors harder to understand, by transforming the referential metaphors into predicative metaphors. We directly tested whether it is their referential function that made the metaphors more difficult to comprehend.

\section{EXPERIMENT 1}

Previous work on metaphor has shown that, given adequate contexts, people need not interpret figurative phrases literally before understanding the intended figurative meaning. This makes Gibbs's (1990) finding that metaphoric referential descriptions take longer to read than literal ones difficult to understand. One possible explanation that he gives for this result is that his metaphors differed from the stimuli used in other psychological studies because his metaphoric descriptions were "very hard to imagine as having a literal meaning in any context"' (p. 58), whereas in some other experiments, the phrases had both literal and metaphoric interpretations, depending on the context (see, e.g., Ortony et al., 1978). It is not clear why having no possible literal interpretation would make metaphoric interpretation more difficult, but this was a difference with respect to the stimuli from previous experiments, and might therefore have been responsible for a difference in the results (see, however, Experiment 3).

Another possible explanation is that Gibbs's (1990) context stories did not endow the characters in the stories with enough shared knowledge. Clark and Marshall (1981) have argued that such shared (mutual) knowledge is necessary for successful communication. Furthermore, Gibbs (1987) demonstrated earlier that readers were aware of the knowledge shared by the characters in stories. He found that subjects attributed different utterances to characters based on knowledge shared by the characters, rather than on facts known to the omniscient reader. Perhaps, in Gibbs's (1990) stories, the characters' mutual knowledge was not clear to the readers. Take for example, Gibbs's (1990, p. 59) sample metaphoric story:

Stu went to see the Saturday night fights.

There was one boxer that Stu hated.

This guy always lost.

Just as the match was supposed to start, Stu went to get some snacks.

He stood in line for ten minutes.

When he returned, the bout had been canceled.

"What happened?"' Stu asked a friend.

The friend replied, "The creampuff didn't even show up."

Until the word creampuff occurs, it is not clear from the context that Stu and his friend share attitudes (or even knowledge of Stu's attitude) toward the wimpy fighter. This might cause the reader to hestitate upon reading the word creampuff, wondering why Stu's friend refers to the boxer in this manner, since neither the friend's knowledge of, nor the friend's attitude toward, the fighter has ever been described. Thus, the term creampuff not only refers to the fighter, but also adds information about the friend's attitude. In Gibbs's literal condition, the last line had the word fighter instead of creampuff. The use of fighter does not provide additional information about shared attitudes of Stu and his friend. The need to integrate extra information in the metaphoric condition might be responsible for the increased reading time. 
To examine this possibility, we constructed contexts for use in Experiment 1-short vignettes in which two people were talking about a mutually known object or person. There were two experimental conditions. In the literal condition, a word was used that could literally refer to an object or person that had been introduced previously in the story context. In the metaphoric condition, a term was used that could not be taken as literally picking out the intended referent from the discourse model. The metaphoric references, while literally anomalous, were intended (on the basis of the characters' beliefs and attitudes) to refer unambiguously to a particular object or person in the story context. Because the relevant attitudes and situations had already been presented, little information was added by the use of a metaphoric referring term instead of a literal one.

It was expected that ensuring mutual knowledge between the characters in the stories would prevent any difficulty in comprehending the metaphoric references. That is, contrary to the findings of Gibbs (1990), the reading times for the crucial sentences would not differ between the literal and the metaphoric conditions.

\section{Method}

Subjects. Eighteen Brown University undergraduates volunteered to participate in Experiment 1 for payment. All were native speakers of English.

Materials. The stimuli were 20 story contexts in which two people discussed a mutually known object or person. The stories were from 4 to 8 lines long (mean, 6.4), with one sentence per line. The crucial sentence appeared as either the last or the penultimate sentence in the story. It always involved one character making a reference to a previously mentioned object or person. This sentence had two versions, in which only the referring nouns differed. In the literal condition, the referring noun was a word that could literally apply to the object or person being referred to. The referring nouns either were synonyms of the word used earlier in the story, or were related through a category hierarchy-for example, fighter to refer to a boxer (synonym), cat to refer to a pet siamese (superordinate relation), or surgeon for a doctor (subordinate relation). In the metaphoric condition, the referring noun could not be construed as literally describing the person or object under discussion. For example, the boxer was referred to as a creampuff, or the cat as a princess. Given the story contexts, the metaphors were intended to be appropriate. A complete list of metaphors and phrases may be found in Appendix A. Here is a complete story context, with its two experimental sentences:

Felicia was a feline fanatic, who had two persians and a siamese.

The siamese was her favorite, and she treated it like a child. One day it would not eat its food, though Felicia tried to coax it.

After babying it for an hour, to no avail, she became worried. She called Joseph, her usual veterinarian, for advice.

He was well aware of Felicia's doting attitude towards her pets.

"My cat won't eat," she informed him. (literal)

"My princess won't eat," she informed him. (metaphoric)

Joseph said, "Bring her in, there's an open slot at noon."

The frequency (Francis \& Kučera, 1982) and length of the literal and metaphoric referring terms were roughly equated across all the stories. In the literal condition, the mean word length was 6.20 let- ters, and in the metaphoric condition, it was 6.15 letters. The mean frequencies were 62 and 34 out of one million for the literal and metaphoric conditions, respectively.

Two lists of stories were created. Each consisted of 20 stories, 10 with literal referring terms and 10 with metaphoric ones. Across the two lists, each story appeared once with its literal referring term and once with the metaphoric one. Half the subjects received each list. To ensure that the subjects were reading the stories, a true-false question followed each one immediately.

Procedure. The subjects first participated in an unrelated memory experiment. The stories and questions were presented on an IBM XT, using the Digitry Experimental Testing System. All stories began with the instruction, "NEW STORY. PRESS ANY KEY TO BEGIN." After the subject pressed a key on a response panel, there was a 500-msec delay before a fixation cross appeared where the sentences would begin. The first sentence appeared $500 \mathrm{msec}$ later. It remained on the screen until the subject pressed the button to get the next sentence, which appeared after a 500 -msec blank screen. The computer recorded the time between sentence presentation and the buttonpress. This continued for the remaining sentences of the story (including the crucial sentence). After the final sentence, the words "TRUE OR FALSE?"' appeared in capitals in the center of the screen. The true-false question appeared after $500 \mathrm{msec}$, and the subject responded by pressing the appropriately marked button on the panel. The response time to the question was not recorded.

The subjects received an instruction sheet, which explained the procedure and informed them that the reading times were being recorded. The instructions emphasized that it was important to understand each sentence fully before continuing. The subjects read three practice stories before the start of the experiment proper. Each subject received the stories in a different random order. The experiment took 15-20 min to complete.

\section{Results and Discussion}

Error rates for the true-false questions were low and approximately equal across conditions (mean error: literal condition, $5 \%$; metaphoric condition, $7 \%$ ). Since the questions did not refer to the crucial sentence, they cannot be used to determine whether there was a speed-accuracy tradeoff. The questions were included to ensure that the subjects would attend to the story contexts. If a subject had answered close to the chance level, it would have been necessary to discard his/her data. This was not necessary for any subject.

As for the reading times for the crucial sentence, the expected result was that the two conditions would be roughly equal. However, no subject read the metaphoric referring sentences faster than the literal ones. The means were $1,669 \mathrm{msec}$ in the literal condition and $2,000 \mathrm{msec}$ in the metaphoric condition. This result is highly reliable by a two-tailed sign test $(p<.0001)$. The times for the literal condition were faster than those for the metaphoric condition in 18 of the 20 stories $(p=.0004)$. The standard error of the mean difference between the metaphoric and literal conditions was $61 \mathrm{msec}$.

In contrast to recent work on comprehension of metaphors, Experiment 1 shows that metaphoric reference does take longer to comprehend than literal reference. These results replicate the findings of Gibbs (1990), but using different metaphors and stories. Furthermore, this result occurred even though the characters' mutual knowl- 
edge of the metaphoric relation was ensured. A number of the topics and vehicles used in this experiment were adapted from the materials of Gildea and Glucksberg (1983), where they were shown to be comprehended as easily as literal expressions. This suggests that it is probably not difficulty in finding metaphoric relations between the topic and vehicle that made these metaphors difficult to understand (see also Experiment 3). One significant difference between these two experiments is that Gildea and Glucksberg did not use the metaphors referentially. In their experiment, the topic and vehicle appeared in the sentences together, as in Some cats are princesses. It therefore seems likely that the difficulty subjects had in interpreting the metaphors in this experiment was due to their use as referring expressions.

\section{Rating Analyses of Experiment 1}

One possible reason that the metaphoric referring expressions were more difficult to comprehend is that these expressions may not have picked out the intended referent specifically enough. In a literal referring expression, readers usually have no difficulty deciding what person or object the speaker is referring to. That is, if one is talking about boxers at a boxing match, and someone mentions a fighter, the semantic similarity of the two terms makes it clear that the speaker has not changed the topic of conversation. On the other hand, if a creampuff is suddenly brought up, the connection between the word and referent is obscure, since the two are not very similar. That is, perhaps the metaphors simply did not pick out the referent accurately enough.

We created questionnaires from the stimulus lists used in Experiment 1 in order to discover how comprehensible the references, both literal and metaphoric, were. Unfortunately, it is likely that subjects rating this question would be swayed by the difficulty of processing the metaphoric references-that is, it is not clear that such ratings would be independent of the results of Experiment 1 itself, and therefore they may not provide a separate explanation of its results. But our goal was to select a subset of stimuli that had very clear metaphoric references, for which we could reexamine the differences in response time between the two conditions.

In order to reduce the influence of processing difficulty, we did not present the original sentences, in which the metaphors were clearly difficult to understand. Instead, we presented the story context up to the crucial sentence. Then we asked "How comprehensible would it be for [the speaker] to refer to [the referent] as "[the referring expression]'?" The description of the referent contained the same word or phrase as had appeared in the story context; the referring expression was either the metaphor or the literal noun phrase. The subjects answered these questions by using a 1-7 scale, where 7 was high. Each subject rated each story context once, receiving either the literal or the metaphoric reference.

Not surprisingly, given the results of Experiment 1, the literal expressions were rated as being more comprehensible, receiving a mean of 5.76 , as opposed to 4.72 for the metaphors. However, we were able to select a set of 14 items that had equivalent mean ratings in the two conditions: 5.45 and 5.40. An analysis of these items' reading times in Experiment 1 showed that there was still a sizeable 196-msec advantage for literal references $[t(13)$ $=2.34, p<.05]$. Thus, even when the references were equated for rated comprehensibility, the metaphors took significantly longer to understand.

Another possible explanation of the difference between metaphors and literal phrases (suggested by a reviewer) is that the metaphors may have added new, "characterizing" information not present in the literal reference. For example, in calling the boxer the creampuff, the speaker may be giving new information about his feelings about the boxer that was not present in the literal label, fighter. Recall that the stories were written so that the metaphors would be fully consistent with the characters' common ground, so there should not have been such differences. However, it may be that we were unsuccessful in constructing such stories, and therefore we conducted another posttest of the stimuli to discover whether the metaphors and literal phrases differed in how much new information they included.

In the posttest, we used a questionnaire very similar to the one just described. The subjects were 18 different University of Illinois undergraduates. The questionnaire presented the first portion of the story, up to the crucial sentence. Then subjects were asked "How consistent would it be for [the speaker] to refer to [the referent] as '[the crucial phrase]'?" The crucial phrase was either the literal or the metaphoric reference. In the instructions, the subjects were asked to rate the phrase on how inconsistent or surprising it would be if they were to hear it used to refer to the indicated object in that context. They were given a highly consistent and a highly inconsistent reference as examples. The subjects rated each phrase on a 1-7 scale, where 1 meant perfectly consistent, not surprising and 7 meant very inconsistent or surprising. Thus, if metaphors included new or inconsistent information not included in the literal references, they would receive higher ratings. There were two versions of the questionnaire, differing in whether each story had the literal or the metaphoric reference.

The results showed that the metaphors were slightly but nonsignificantly more surprising/inconsistent than the literal references. The mean ratings were 2.94 for metaphors and 2.19 for literal phrases $[t(19)=1.45, p>$ .10]. When the four items with the greatest metaphoricliteral disparity were removed, the difference between the two conditions was eliminated (mean difference $=.005$ ), but there was still a significant $278-\mathrm{msec}$ advantage in reading times for the remaining items $[t(15)=3.03$, $p<.01]$.

In short, the difference in ratings between the two conditions was not reliable, and when it was eliminated entirely, it still took considerably longer to comprehend metaphors. We conclude, then, that the problem with the metaphors is not that they presented new or inconsistent information. Experiment 3 reinforces this conclusion. 


\section{EXPERIMENT 2}

In an attempt to clarify the references of the metaphors, the stories from Experiment 1 were adapted slightly, to make the intended referent as salient as possible. Perhaps if there could be no doubt about what the speaker was referring to, it would not matter whether the referring expression was literal or metaphoric. Mentioning the referent just prior to the sentence with the referring expression might eliminate any problem in identifying the intended referent.

\section{Method \\ Subjects. Eighteen Brown University undergraduates or recent graduates volunteered to participate for payment. None had partic- ipated in the previous experiment. \\ Materials. The materials of Experiment 2 were nearly identical to those of Experiment 1. The stories were adapted slightly, to make the intended referent very clear. As is shown in the sample story below, this clarification was accomplished by adding a sentence that explicitly mentioned the referent immediately before the cru- cial sentence. This made the story lengths from 5 to 9 lines, with a mean of 7.3 lines. An attempt was made to keep changes to a minimum, especially in the test sentences, so that the two experi- ments could be compared. However, in two cases, the addition of the extra sentence made it necessary to modify the crucial sentence as well. Here is a sample story:}

Felicia was a feline fanatic, who had two persians and a siamese. The siamese was her favorite, and she treated it like a child. One day it would not eat its food, though Felicia tried to coax it. After babying it for an hour, to no avail, she became worried. She called Joseph, her usual veterinarian, for advice.

He was well aware of Felicia's doting attitude towards her pets.

Felicia described her problem with her siamese

[sentence added in Experiment 2]

"My cat won't eat," she informed him. (literal)

"My princess won't eat," she informed him. (metaphoric)

Joseph said, "Bring her in, there's an open slot at noon."

Procedure. The procedure was identical to that of Experiment 1.

\section{Results and Discussion}

The error rates for the true-false question were again nearly equal for the two conditions: literal condition, $3 \%$, and metaphoric condition, $5 \%$. No subject had to be removed because of high error rates.

The results again showed that the metaphoric sentences were more difficult to understand than the literal sentences. The mean reading times were 1,912 and $2,262 \mathrm{msec}$ for the literal and metaphoric conditions, respectively. Seventeen of the 18 subjects were faster in the literal condition $(p=.0002)$, and 17 out of 20 stories were faster in the literal condition $(p<.003)$ by two-tailed sign tests. The standard error of the mean difference between the metaphoric and literal conditions was $58 \mathrm{msec}$.

Finally, since the stories in Experiments 1 and 2 were nearly identical, it is possible to compare the two experiments. The mean difference between the literal and metaphoric conditions for each subject were calculated, and these scores for Experiments 1 and 2 were compared. The average difference between the metaphoric and literal conditions were 332 and $350 \mathrm{msec}$ in Experiments 1 and 2, respectively. These means did not differ reliably $[t(34)=$ $.21, S E=84]$. In fact, there was a slight trend for a larger difference in the second experiment, when the reference was expected to be easier.

\section{EXPERIMENT 3}

The results of the first two studies eliminate some salient hypotheses about why referential metaphors are more difficult to understand. But with these hypotheses eliminated, other explanations need to be considered. In particular, we began to worry that referential metaphors might be less apt than predicative metaphors. Because Gibbs (1990) found similar results with different stimuli, it seems unlikely that both our studies just happened to use poor metaphors. It is more likely that the kinds of metaphors that one naturally creates in referential contexts might be less apt than those chosen for predicative constructions ( $A$ is a $B$ constructions). Thus, it seemed necessary to compare the same metaphors in referential and predicative constructions.

In Experiment 3, we did just that, by changing the referential metaphors used in Experiments 1 and 2 into predicative metaphors in which the topic was the subject and the vehicle occurred in the predicate. So, instead of the sentence The creampuff didn't even show up, the target sentence might be That boxer is a creampuff. If the quality of the metaphors caused the difficulty in the comprehension of our references, this poor quality should have made the metaphors just as difficult to understand in the predicative construction. If however, literal and metaphoric sentences of this form take approximately the same amount of time to read, the implication would be that it was not the poor quality of these metaphors that caused the difficulty, but rather the use of the metaphor as a referring expression.

\section{Method}

Subjects. Eighteen Brown University undergraduates and recent graduates participated in Experiment 3 for payment. None had participated in the previous experiments.

Materials. The materials for Experiment 3 were nearly identical to those of Experiment 1 . The only change occurred in the crucial sentence. In the metaphoric condition, the crucial sentence was altered so that the topic and vehicle of the metaphor were both explicit in the sentence, and in the standard $A$ is $a B$ form. The literal condition used the same subject, as well as a noun or adjective in the predicate that literally described it (in place of the metaphor's vehicle). This noun or adjective did not occur in the stories in the previous experiments, but it was necessary to introduce these items in order to create comparable paraphrases. Appendix B gives a complete list of the test items; here is a sample story:

Felicia was a feline fanatic, who had two persians and a siamese The siamese was her favorite, and she treated it like a child. One day it would not eat its food, though Felicia tried to coax it. After babying it for an hour, to no avail, she became worried. She called Joseph, her usual veterinarian, for advice.

He was well aware of Felicia's doting attitude towards her pets.

"The cat is my favorite," she informed him. (literal)

"My cat is my princess," she informed him. (metaphoric)

Joseph said, "Bring her in, there's an open slot at noon." 
The frequency and length of the predicates between the two con ditions were roughly equated. The mean word lengths were 6.85 and 6.20 letters for the literal and metaphoric conditions, respectively. The mean frequency out of one million was 35 in the literal, and 31 in the metaphoric, condition (Francis \& Kucera, 1982). Because the metaphors were all nouns, and because many of the literal paraphrases were not, the metaphors often included an additional article in the test sentence (see Appendix B). This would create a bias against our expected results of equivalent reading times for metaphors

Procedure. The procedure was identical to those of the first two experiments. The subjects participated in a brief (5- to $10-\mathrm{min})$, unrelated memory experiment before doing this task.

\section{Results and Discussion}

The error rates across subjects were low and equal for the two sentence types ( $4 \%$ errors).

In this study, the reading time difference between the literal and metaphoric conditions was eliminated. Mean reading times were $2,146 \mathrm{msec}$ in the metaphoric condition and $2,054 \mathrm{msec}$ in the literal condition, not a reliable difference $[t(17)=1.36, p>.10, S E=66$, by subjects; $t(19)=.70, p>.10, S E=147$, by items]. Is this null result simply a slightly weakened effect, or does it represent a real change from the previous differences? Since these stories were nearly identical to those of Experiment 1, we compared the difference scores (metaphor minus literal) of the subjects in Experiments 1 and 3. The mean difference score of Experiment $1(332 \mathrm{msec})$ was found to be reliably larger than that of Experiment 3 (92 $\mathrm{msec}$ ) $[t(30)=2.60, p<.02, S E=92]$. Thus, placing referential metaphors in a predicate significantly reduced their comprehension difficulty relative to literal sentences.

Experiment 3 replicated the standard finding in metaphor research - that in context, metaphors can be understood as readily as similar literal statements. This result shows that the particular topic-vehicle relations used in this series of experiments can be as easy to understand as literal paraphrases. (Also, the difficulty of metaphoric reference cannot be due to the story contexts, which were the same in Experiments 1 and 3.) Since it is not the particular metaphors that caused the comprehension difficulty in Experiments 1 and 2, it must have been their use in referring expressions that caused the increased reading times.

\section{GENERAL DISCUSSION}

These experiments on literal and metaphoric referring expressions were intended to increase our understanding of the comprehension of literal and figurative language. In many previous experiments, metaphors of the general form The $A$ is $a B$ have been used (Gildea \& Glucksberg, 1983; Glucksberg et al., 1982; Keysar, 1989), and they have proved to be no slower to understand than literal interpretations. It is important to discover whether the same results would be found with metaphors in other forms.

The first two experiments replicated the finding of Gibbs (1990) that metaphoric reference is more difficult than literal reference, disconfirming a number of explanations of this effect. Experiment 1 ensured that the characters in the context stories shared mutual knowledge of the attitudes and situations necessary to properly interpret the reference. Experiment 2 was an attempt to make the intended referent more salient, by placing it in the sentence just prior to the crucial sentence. Neither of these manipulations reduced the reading time difference between the metaphoric and literal conditions. The comprehension of metaphoric referential expressions was still considerably slower than that of their literal counterparts. Experiment 3 revealed that the same metaphors, when placed in a sentence predicate, were no harder to understand than literal paraphrases. Thus, it is the use of metaphors in references that causes this effect-it is not a result of referential metaphors' being less apt.

The question arises, why does it take longer to comprehend the combination of reference and metaphor? The longer reading times in the metaphoric condition do not seem to be caused by inaccessibility of the intended referent, as is shown by the results of Experiment 2. Since the referents in this experiment were emphasized in the sentence immediately before the test sentence, they should have been easily accessible from the discourse representation. However, the metaphoric condition was still significantly slower than the literal. Gibbs (1990) found that after subjects read referring expressions, both literal and metaphoric, the appropriate antecedent was activated. That is, both literal and metaphoric referring expressions reliably reinstate their antecedents to about the same degree, as measured by recognition memory times. This result does not answer the question of whether initial access of metaphoric and literal referents takes the same amount of time, since his probes occurred after the sentence was fully integrated. However, this finding does show that metaphoric references are understood by accessing previous discourse elements, just as literal references are.

Gibbs (1990, p. 58) suggested that one reason why researchers have found that metaphors are easy to understand is that many of the sentences that they used can be construed either metaphorically or literally (e.g. , Ortony et al., 1978), so that even the metaphors were well formed on one reading. He pointed out that referential metaphors like The creampuff didn't even show up are often semantically anomalous, having no clear literal meaning, and he suggested that this might cause them to be more difficult to understand. However, if this were correct, the predicative metaphors that we used in Experiment 3 would have been equally difficult to understand: The boxer is a creampuff is also semantically anomalous on a literal reading. However, these sentences were no more difficult to interpret than literal sentences were. Thus, this characteristic does not seem to explain why referential metaphors are more difficult than predicative metaphors.

Another possible explanation for the advantage of literal reference is lexical semantic priming. That is, the literal noun might have been primed by the context more than the metaphoric noun was, since the literal referring expressions were semantically closer to the intended antece- 
dents than the metaphoric expressions were. This is normally the case, because, if the two parts of a metaphor are too closely related, the expression will not seem metaphoric; and if the literal referring phrase is too semantically distant from its antecedent, the reference will not be literal. Perhaps the similarity of meaning in the literal condition enabled the subjects to identify the literal nouns more quickly.

However, semantic priming or word association has been effectively argued against as an explanation of metaphor comprehension (Camac \& Glucksberg, 1984). Furthermore, semantic priming cannot explain the difference between referential and predicative metaphors. Finally, the size of the metaphor effect in Experiments 1 and 2 was considerably larger than most effects of semantic priming. Comprehension of metaphors was over $300 \mathrm{msec}$ slower than that of literal sentences in those experiments, whereas semantic priming of lexical decision is usually on the order of $25-75 \mathrm{msec}$ (e.g., de Groot, 1990; Meyer \& Schvaneveldt, 1971). Thus, it seems unrealistic to attribute the difference between literal and metaphoric sentences to lexical priming of the literal word.

The traditional analysis of metaphor described in the introduction provides one explanation of the difference between referential and predicative metaphors. Recall that metaphors have often been divided into three components: the topic, the vehicle, and the ground that connects them. In a predicative metaphor, such as $M y$ cat is a princess, the topic and vehicle are mentioned, and the listener must work out the ground. But in a referential metaphor such as My princess won't eat (referring to a cat), the listener must infer both the topic (cat) and the ground (the adulation and special treatment given to royalty and some pets). Thus, referential metaphors are clearly "missing" more of their interpretation than predicative metaphors are: They lack the topic as well as the ground. The selection of the topic and ground is not impossible, because an appropriate context provides information that constrains both. (Gibbs, 1990, p. 58, says that his metaphoric references "did not include explicit mention of the topic and vehicle terms," which does not seem correct, since the referring expression is in fact the vehicle in the complete metaphor. However, Gibbs may mean that in a referential metaphor, there is no clear statement of the metaphor's components, which makes it difficult to identify it as a metaphor. This is similar to our argument.)

One might criticize this proposal in light of the results of Experiment 2. There, the intended referent was highlighted just before the metaphoric sentence. Wouldn't readers know that the description referred to the correct referent? If so, the topic of the metaphor would not truly be missing, and the proposed explanation would not explain the results. However, even in Experiment 2, the metaphoric topic had to be inferred. For example, imagine that the sentence preceding the metaphor was Joe gave his opinion about the doctor, and the metaphoric sentence began The butcher. . . Certainly, the discourse referent of the doctor will be highly activated. However, it is still not necessarily the case that Joe is referring to the doctor with the phrase the butcher. For example, the sentence could have continued, The butcher was almost crippled by that guy, or The butcher would do a better job than he would. The initial phrase by itself does not decisively pick out the correct referent, even in Experiment 2-it is only in the context of the whole sentence's interpretation that the referent can be determined (as has been found with literal reference as well; see Clark, Shreuder, \& Buttrick, 1983). Because the noun phrase is not semantically related to the referent, the topic of the metaphor needs to be inferred. Or, to put it another way, the fact that the phrase is metaphorical needs to be inferred, since much of the metaphor is only implicit.

How is the reference determined? The processes of interpreting the metaphor and identifying the referent are intertwined. Comprehension of the metaphor depends on what the phrase refers to, and determining the reference depends on which reference assignment results in a coherent (metaphoric) interpretation. For example, to understand the reference of my princess in My princess won't eat requires that one understand that the metaphor My cat is a princess is intended. In contrast, there is little ambiguity as to what is being discussed in metaphors that occur in the familiar predicate form. Thus, That doctor is a butcher does not require the reader to infer the metaphor's topic; the doctor is explicitly mentioned. So, referential metaphors require that metaphoric interpretation and the reference be worked out simultaneously, whereas predicative metaphors require that only the former be constructed.

This explanation is consistent with Gibbs's (1990) account of the difficulty of metonymic reference, as when one refers to a surgeon as the scalpel. He argues that such descriptions could have referred to an actual scalpel, whereas metaphoric descriptions, like the butcher, have no such interpretation. Putting Gibbs's and our explanations together, we arrive at the following explanation of the order of difficulty of these forms. Literal references in these stories are understood through the similarity between the word meaning and the properties of a particular known referent. Metaphoric references are more difficult, because they require the topic and ground to be inferred. However, if the metaphor is apt, the metaphoric meaning should pick out a specific referent fairly unambiguously. Metonymic references are more difficult still, because they receive competition from plausible alternative interpretations-that is, the sentence truly could be referring to a scalpel, and this possibility competes with the correct one. Such plausible alternatives are not present in the metaphor (e.g., no butcher was mentioned in the story about Joe's disastrous operation, and literal butchers had no obvious place in the story).

In retrospect, the results for referential metaphor are somewhat similar to those of Gerrig and Healy (1983), although the similarity is somewhat masked by differences in terminology. Part of Gerrig and Healy's study involved the comparison of forward and backward orders of nomi- 
nal metaphors. Because these metaphors occurred in isolated sentences, they did not actually refer to anything in a discourse. Nonetheless, they found an order effect relevant to the current discussion. Their stimuli included metaphors like The train followed the parallel ribbons. In this example, the metaphoric material (the ribbons, meaning train tracks) followed the context (the train), which helped in its interpretation. In a different condition, the sentence was passivized and the metaphoric material appeared first: The parallel ribbons were followed by the train. Notice that the metaphor itself ("the tracks are parallel ribbons") is not explicitly stated; the topic has been omitted, as in the referential metaphors studied in the present article. Gerrig and Healy found that the second order was much more difficult to understand, a difference that was much larger for metaphors than for literal controls. An explanation of this effect can be given that is similar to the one we have provided for referential metaphor: When the context appears first, the metaphoric material is easily interpreted as a metaphor, because the context provides information about the metaphor's topic (trains are closely associated with tracks), but when the metaphoric vehicle appears first, the reader initially has no reason to think that the phrase is metaphoric. Thus, although Gerrig and Healy's experiment did not include exactly the same metaphoric constructions as those studied here or by Gibbs, our explanation can encompass the results from all three.

A possible contributing factor to this effect is suggested by research on anaphora. In all of our stories, the metaphor referred to a previously described referent. Sanford and Garrod (1981) note that "anaphoric reference will have to fall within the Given information in the sentence" (p. 93). That is, anaphors generally contain known information that allows the referent to be identified; usually, they do not contain new information. Since one of the purposes of using a metaphor is "to plug semantic gaps" for which "there are no literal expressions that convey what it means" (Searle, 1979, p. 97), or to say things that are "inexpressible" (Ortony, 1980), it is not clear how metaphor could be used without the addition of considerable new information. Recently, Tourangeau and Rips (1991) argued that good metaphors are not based on the normal features of the topic or ground, but on "emergent" features. If this is the case, metaphor used as anaphoric reference as in our and Gibbs's stories would necessarily break the given-new contract. One way to test this hypothesis would be to examine nonmetaphoric epithets, which could violate the given-new contract in the same way. For example, instead of a pronoun, one might substitute the jerk or the sweetheart, when the personality characteristics being referred to had not yet been indicated in the text. Such cases might also be difficult to understand, since they add (or presuppose) new information about the referent. However, it is not clear whether they would be as difficult to understand as metaphoric references.

These studies require a rethinking of what circumstances make literal and metaphoric sentences equally easy to understand. As we remarked above, it does not seem nec- essary for a metaphor to have a well-formed literal meaning in order for it to be easily comprehensible. Past explanations of metaphor comprehension have focused on how well the metaphoric material can be incorporated into a discourse model or schema (Gerrig \& Healy, 1983; Gibbs, 1984; Keysar, 1989; Ortony et al., 1978; Rumelhart, 1979). They have argued that as long as the context supports the metaphoric interpretation, there is no need for any special "metaphoric processing," and the metaphor can be assimilated into the text representation just as other information is. However, this view assumes that the metaphor is properly marked in the text. For example, Their marriage is a prison clearly connects the metaphoric vehicle (the prison) to its topic (their marriage), which is probably also a topic of the conversation. In The creampuff didn't even show up, the vehicle is not explicitly related to the topic (the boxer). Given the results of Experiment 3, it seems that comprehending the metaphor (i.e., relating the topic and vehicle) is not the difficulty here-the problem is identifying the referent and (equivalently) identifying the noun phrase as metaphorical.

It is tempting to try to decide which of two causes makes this so difficult: that of identifying the metaphor, or that of identifying the referent? We have argued that these two processes are largely identical in this case, since the best referent is the one that gives a satisfying metaphoric meaning, and the metaphoric meaning is completely dependent on which referent is chosen. Thus, the results for referential metaphor do not challenge the claim that metaphoric "comprehension" is no more difficult than literal comprehension, when there is an appropriate context. However, it must also be admitted that the use of nonliteral referring expressions may not only make it more difficult to determine the references, but may qualitatively change the interpretation process. This may be a property not of metaphor alone, but of any reference in which the referring expression's meaning is not highly related to the properties of the referent. In all such cases, interpreting the phrase may depend on determining the referent-and vice versa.

\section{REFERENCES}

Camac, M. K., \& Glucksberg, S. (1984). Metaphors do not use associations between concepts, they are used to create them. Journal of Psycholinguistic Research, 13, 443-455.

Clark, H. H., \& Marshall, C. R. (1981). Definite reference and mutual knowledge. In A. K. Joshi, B. L. Webber, \& I. A. Sag (Eds.), Elements of discourse understanding (pp. 10-63). Cambridge: Cambridge University Press.

Clark, H. H., Schreuder, R., \& Buttrick, S. (1983), Common ground and the understanding of demonstrative reference. Journal of Verbal Learning \& Verbal Behavior, 22, 245-258

DE Groot, A. M. B. (1990). The locus of the associative-priming effect in the mental lexicon. In D. A. Balota, G. B. Flores d'Arcais, \& K. Rayner (Eds.), Comprehension processes in reading (pp. 101123). Hillsdale, NJ: Erlbaum.

Dell, G. S., McKoon, G., \& RatclifF, R. (1983). The activation of antecedent information during the processing of anaphoric references in reading. Journal of Verbal Learning \& Verbal Behavior, 22, 121-132. 
FRANCIS, W. N., \& KUČERA, H. (1982). Frequency analysis of English usage: Lexicon and grammar. Boston: Houghton Mifflin.

GerRIG, R. J., \& HeAly, A. F. (1983). Dual processes in metaphor understanding: Comprehension and appreciation. Journal of Experimental Psychology: Leaming, Memory, \& Cognition, 9, 667-675.

GiBss, R. W. (1984). Literal meaning and psychological theory. Cog. nitive Science, 8, 275-304.

GiBBS, R. W. (1987). Mutual knowledge and the psychology of conversational inference. Journal of Pragmatics, 11, 561-588.

GisBs, R. W. (1990). Comprehending figurative referential descriptions. Journal of Experimental Psychology: Learning, Memory, \& Cognition, 16, 56-66.

GibBs, R. W., NAGAoKA, N. (1985). Getting the hang of American slang: Studies on understanding and remembering slang metaphors. Language \& Speech, 28, 177-194.

GILDEA, P., \& GluCKsBerg, S. (1983). On understanding metaphor: The role of context. Journal of Verbal Learning \& Verbal Behavior 22, 577-590.

GlucksBerg, S., GildeA, P., \& Bookin, H. G. (1982). On understanding nonliteral speech: Can people ignore metaphors? Journal of Verbal Leaming \& Verbal Behavior, 21, 85-98

Grice, H. P. (1975). Logic and conversation. In P. Cole \& J. Morgan (Eds.), Syntax and semantics 3: Speech acts (pp. 41-58). New York: Academic Press.

Hoffman, R. R., \& Honeck, R. P. (1980). A peacock looks at its legs: Cognitive science and figurative language. In R. P. Honeck \& R. R. Hoffman (Eds.), Cognition and figurative language (pp. 3-24). Hillsdale, NJ: Erlbaum.

KEYSAR, B. (1989). On the functional equivalence of literal and metaphorical interpretations in discourse. Journal of Memory \& Language, 28, 375-385.

Meyer, D. E., \& SchVaneveld, R. W. (1971). Facilitation in recog nizing pairs of words: Evidence of a dependence between retrieval operations. Journal of Experimental Psychology, 90, 227-234.

MiLLER, G. A. (1979). Images and models, similes and metaphors. In A. Ortony (Ed.), Metaphor and thought (pp. 202-250). Cambridge: Cambridge University Press.

O'Brien, E. J., Duffy, S. A., \& Myers, J. L. (1986). Anaphoric inference during reading. Journal of Experimental Psychology: Learning, Memory, \& Cognition, 12, 346-352.

ORTONY, A. (1980). Some psycholinguistic aspects of metaphor. In R. P. Honeck \& R. R. Hoffman (Eds.), Cognition and figurative language (pp. 69-86). Hillsdale, NJ: Erlbaum.

Ortony, A., Schallert, D. L., Reynolds, R. E., \& Antos, S. J (1978). Interpreting metaphors and idioms: Some effects of context on comprehension. Journal of Verbal Learning \& Verbal Behavior, 17, 465-477.

RedDy, M. J. (1969). A semantic approach to metaphor. In Papers from the fifth regional meeting, Chicago Linguistics Society (pp. 240-251) Chicago: University of Chicago, Department of Linguistics.

RUMelhart, D. E. (1979). Some problems with the notion of literal meanings. In A. Ortony (Ed.), Metaphor and thought (pp. 78-90). Cambridge: Cambridge University Press.

SANFORD, A. J., \& GARRROD, S. C. (1981). Understanding written language: Explorations of comprehension beyond the sentence. Chichester, U.K.: Wiley

Searle, J. R. (1979). Metaphor. In A. Ortony (Ed.), Metaphor and thought (pp. 92-123). Cambridge: Cambridge University Press.

SHINנo, M., \& MYeRS, J. L. (1987). The role of context on metaphor comprehension. Journal of Memory \& Language, 26, 226-241.

Tourangeau, R. (1982). Metaphor and cognitive structure. In D. S. Miall (Ed.), Metaphor: Problems and perspectives (pp. 14-35). Sussex, U.K.: Harvester Press.

TOURANGEAU, R., \& RIPS, L. (1991). Interpreting and evaluating metaphors. Journal of Memory \& Language, 30, 452-472.

Tourangeau, R., \& STERnBerg, R. J. (1981). Aptness in metaphor. Cognitive Psychology, 13, 27-55.
APPENDIX A

Items from Experiments 1 and 2

The word on the first line of each entry (e.g., clock) is the intended referent paraphrased from the context story. This is followed by the complete sentence with the referring terms of the two conditions, LITERAL/METAPHORIC

1. clock*

"I did, but the ALARM/ROOSTER didn't work, ' Josette explained.

2. escaped convict*

"Have you seen this FUGITIVE/BIRD?" the police officer asked.

3. pregnant woman*

"Mom," cried Suzie, "look at her STOMACH/BarRel."

4. aloof husband

"I'm glad I wasn't married to that PERSON/ICEBox," said Emily.

5. pampered siamese*

"My CAT/PRINCESS won't eat," she informed him

6. incompetent doctor*

"I guess I'll pass on that SURGEON/BUTCHER," said Mickey.

7. pushy rug seller*

"I never buy from that type of SALESPERSON/BULLDOZER," added Miles.

8. menacing stare

Yoko said, "I'm glad that GLARE/DAGGER isn't directed at me."

9. disorganized work area*

"I could never work at that DESK/JUNKYARD,"' said Melanie.

10. large blouse*

"You take that SHIRT/TENT off this instant."

11. piece of ice*

Karen said, "Those ICICLES/KNIVES are dangerous."

12. excellent plan*

She said, "I wanted to thank you personally for that IDEA/GEM.",

13. gang members

"Just look at those wild CHILDREN/ANIMALs."

14. unassertive teacher

"'That TEACHER/PUTTY couldn't stand up to a two year old."

15. confusing college registration

"Can you explain this system/MAzE to me?' she asked.

16. demanding lecture $\ddagger$

Damien said, "I'm glad that CLASs/NIGHTMARE is over."

17. money

Rich said to Jane, "I guess the REWARD/CARROT wasn't enough."

18. college degree

"Well, I finally have my DIPLOMA/TICKET," said Allison.

19. stubborn elderly man

"The old MAN/WALL won't budge," grumbled Anne.

20. wimpy boxer $\dagger$

"The FIGHTER/CREAMPUFF didn't even show up," said Tracey.

*Items adapted from Gildea and Glucksberg (1983). †Item adapted from Gibbs (1990). \$n an oversight, in this item, the antecedent word was the literal reference. Nonetheless, the item did not show a response time advantage of the literal sentence larger than average. 


\section{APPENDIX B}

Items from Experiment 3

Sentences from Experiment 3, showing the literal adjective or metaphoric vehicle in capitals.

1. "Yes, but the clock was a crummy ALARM/ROOSTER," Josette explained.

2. "This guy is a FUGITIVE/DEviL," the police officer said.

3. "Mom," cried Suzie, "her stomach is HUGE/a BarRel."

4. "Her husband was really ASOCIAL/an ICEBOX," said Emily.

5. "The cat is my FavorITE/PRINCESS," she informed him.

6. "I guess that doctor is INCOMPETENT/a BUTCHER," said Mickey.

7. "Yes, she was Tenacious/a Bulldozer," added Miles.

8. Yoko said, "That look is FIERCE/a DAGGER."

9. "Disorganized? Her area is a DISGRACE/JUNKYARD," said Melanie.

10. "That shirt is UGLY/a TENT,"

11. Karen said, "Those icicles are SHARP/KNIVES."

12. "Your suggestion was HELPFUL/a GEM," she said.

13. "Those Jets are wild CHILDREn/Animals."

14. He is a cowARD/PUTTY before a third grader."

15. "Registration is a MESs/MAzE," she said.

16. Damien said, "Today's class was TERRIFYING/a NiGHTMARE."

17. "I guess the money was not a large enough REWARD/CARROT,", Rich said to Jane.

18. "Yes, a degree is USEFUL/a TICKET for employment," said Allison.

19. “'He's obstinate/a wald, I can't budge him," grumbled Anne.

20. "He's such a LOSER/CREAMPUFF that he didn't even show up," said Tracey.

(Manuscript received October 23, 1991;

revision accepted for publication April 20, 1993.) 